\title{
Philippine Drug Enforcement Agency (PDEA) XII: Programs and Performance
}

\author{
Ernie C. Cerado \\ Sultan Kudarat State University, Tacurong City, Philippines \\ Cielito E. Llano \\ Philippine Drug Enforcement Agency, Autonomous Region in Muslim Mindanao, Philippines
}

\begin{abstract}
This study focused on describing the implementation of PDEA (Philippine Drug Enforcement Agency) programs and their performance in 2012. These programs were primarily referred to demand and supply reduction while performance centered on community awareness and the agency accomplishments. Forty-two (42) staffs of PDEA and 275 community members served as respondents of this inquiry. Essentially, a descriptive survey design was used employing two sets of validated survey questionnaires to gather data. Findings revealed that PDEA programs $v i s-\grave{a}$-vis demand reduction and supply reduction were well-implemented. Moreover, the respondents indicated that they were "aware" on dangerous drugs, controlled precursors and essential chemicals, provisions of the Comprehensive Dangerous Drugs Act of 2002, common causes of drug use and abuse, and adverse effect of dangerous drugs on health. On agency accomplishments, PDEA XII records showed an average of 102 arrests annually. The agency apprehended these drug criminals in 78 buy-bust operations; a total of 23,408 grams of drugs were seized, and used as evidences in 145 cases filed in courts. Apparently, the use of the same vehicles both for intelligence operations and anti-narcotic entrapment was the most serious problem of the agency. Finally, it was concluded that the implementation of PDEA programs is highly related to community awareness but not to the agency performance.
\end{abstract}

Keywords: drug enforcement, law enforcement, Philippine Law, government programs, agency performance

The threat of drug problem cannot be simply miscalculated. Obviously, it is a global concern. In a recently posted World Drug Report 2014, it is pegged that "in 2012, between 3.5\% and 7.0\% of the world population aged 15-64, had used an illicit drug at least once in the previous year". On the same period, approximately 183,000 drug-related deaths were reported corresponding to a mortality rate of 40 deaths per million among the population aged 15-64. It is also indicated that men are more likely to use drugs than women (United Nations Office on Drugs and Crime [UNODC], 2014).

As early as 1988, the United Nations General Assembly had already adopted a Political Declaration considering that "drugs affect all sectors of society in all countries", particularly, "drug abuse affects the

Corresponding author: Ernie C. Cerado, Ph.D., assistant professor, Colleges of Teacher Education and Graduate Studies, Sultan Kudarat State University; research fields: mathematics education, educational management, and institutional development and management. E-mail: eccphd@yahoo.com.

Cielito E. Llano, Ph.D., acting deputy regional director for operations, Philippine Drug Enforcement Agency-Autonomous Region in Muslim Mindanao (PDEA-ARMM); research fields: public management and institutional development. E-mail: cielito.llano@yahoo.com. 
freedom and development of young people, the world's most valuable asset". In said document, member states expressed their total resolve and commitment to combat the world drug problem through practical action and pooling of resources (United Nations General Assembly, 1998).

Moreover, at a special regional conference held in Myanmar, senior policy, law enforcement, and justice delegates cited that East and Southeast Asia continue to be the world's largest markets for synthetic drugs. It was reported that early on 2008, a program was already initiated to enhance the capacity of states and authorities in these regions to generate, manage, analyze, report, and use synthetic drug and precursor information, and to apply this evidence-based knowledge to strategy, policy and program design, and implementation. Eleven countries in the region include the Philippines accept related assistance from UNODC (United Nations Office on Drugs and Crime) through Global Smart ${ }^{1}$.

Apparently, the wrath of illicit drug activities is universal thus it did not spare the country. In a 2013 PDEA (Philippine Drug Enforcement Agency) Report, it cited that illegal drug trafficking remains as the most pervasive drug activity in the country. Accordingly, drug traffickers never stop discovering innovative ways to hide from viewing their illegitimate transactions and activities. Consistent with the world statistics, the account showed $86.60 \%$ of the personalities arrested related to drugs are male.

Besides, in 2006, a columnist even stated that illegal drug abuse in the country has reached epidemic. His claim was due primarily on observations that illegal drug trade penetrated as far as the police and military establishments. Men in uniforms are allegedly assisting in local ports on the transshipment of drugs to the US and from other countries in Asia. Politicians are even bribed of drug monies. Moreover, poor and affluent family members alike go into drugs ${ }^{2}$.

Most recently, the ASEAN (Association of Southeast Asian Nations) Economic Community (AEC) by 2015 came into being. As envisioned, the AEC will "transform ASEAN into a region with free movement of goods, services, investment, skilled labour, and freer flow of capital"3. The realization of the new regional order might as well promote the proliferation of illegal drug industry at its full in Southeast Asia.

Understanding the state of illegal drugs at the macro level, and the new economic order in progress may not be sufficient. Nonetheless, it is still significant and more logical to examine more specifics of the issue. Locally, the PDEA is the lead government agency that addresses the drug problems (RA 9165-Republic Act No. 9165). Regional offices are likewise set up nationwide to implement the agency major programs.

The accomplishments of the PDEA programs with the coordination of the community and other sectors of society can be further supported if the justice system is also doing its role. The drug law enforcement operations are a reflection that the agency is doing its duties and responsibilities, which could lead to the prosecution of drug cases. Additionally, prosecution of drug cases and conviction of criminals may be impossible without the cooperation of the community (Reyes, 2008). How successful PDEA Region XII did its mandates and performed as an agency in order to eradicate the illicit drug problems in local setting would be the core of this inquiry.

In particular, the study had contemplated on the following objectives:

(1) Determining the implementation of PDEA programs relative to demand reduction and supply reduction;

(2) Assessing the community's level of awareness on dangerous drugs and controlled precursors and

\footnotetext{
1 Retrieved from http://www.unodc.org.

2 Retrieved from http://www.mabuhayradio.com.

3 Retrieved from http://www.asean.org.
} 
essential chemicals, provisions of RA 9165 or the Comprehensive Dangerous Drugs Act of 2002, common causes of drug use/abuse, and adverse effect on health of using dangerous drugs;

(3) Describing the agency's accomplishments in terms of arrests, drug law enforcement operations, and cases filed in court;

(4) Relating the implementation of PDEA programs to the agency's performance;

(5) Finding out the problems met by PDEA in the implementation of its programs.

\section{Conceptual Framework}

RA 9165 or the Comprehensive Dangerous Drugs Act of 2002 provided for the creation of PDEA that was mandated to curb problems relating to illegal drugs. The programs and activities undertaken by the agency are primarily based on its vision, mission, core values, objectives, and strategies that can be lumped into reducing supply and reducing demand (Philippine Drug Enforcement Agency [PDEA], 2009).

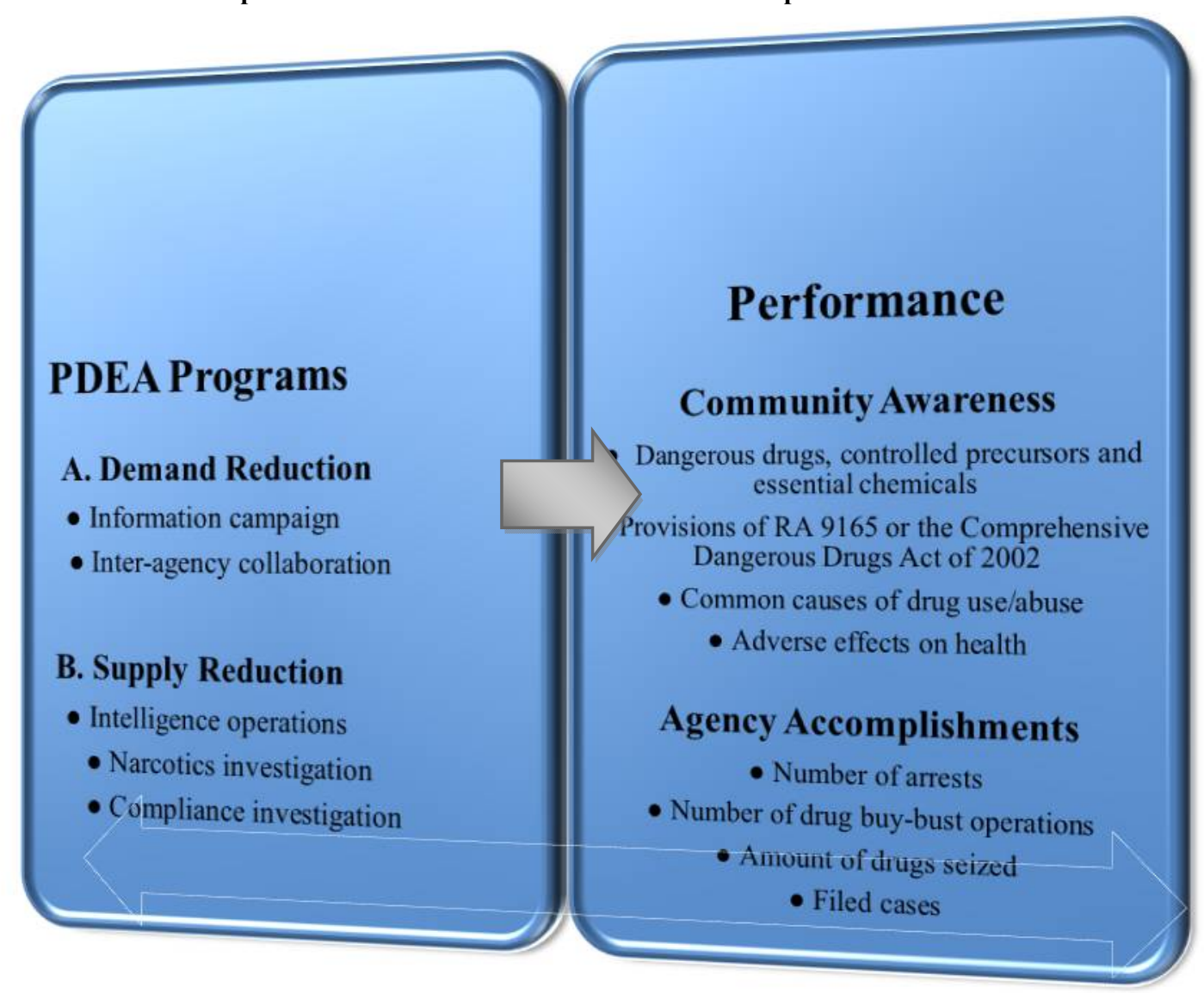

Figure 1. Conceptual paradigm.

Most likely, the majority to benefit from the programs of PDEA are the communities - the general public. Hence, raising the awareness of the whole community about the agency's activities could affect everybody's life and may encourage them to work together to keep things in order. Based on this, PDEA can take advantage of educating the public by effectively teaching each community in the country how to fight drug problems (Rojas, 2009). 
This study relies on the premise that effective implementation of PDEA programs is associated to its performance. As the conceptual paradigm in Figure 1 shows, the independent variables in the study are the PDEA programs of demand reduction and supply reduction. Demand reduction consists of information campaign and inter-agency collaboration as sub-variables. Conversely, supply reduction consists of intelligence operations, narcotics investigation, and compliance investigation.

The dependent variable is PDEA's performance as measured by the level of community awareness, and agency accomplishments like number of arrests effected, number of drug law enforcement operations, amount of drugs seized, and the number of cases filed in court.

\section{Methodology}

In realizing the foregoing ends, a region-wide study was effectively undertaken in 2012 to include the provinces of Cotabato, South Cotabato, Sarangani, and North Cotabato, and the city of General Santos.

Aptly, the descriptive survey method of research was chosen since it involved depicting the existing status of a program and its performance and that necessary data were obtained through survey means and documentary analysis. Moreover, this investigation made use of purposive and random sampling schemes in getting the number of respondents from the agency and the community, respectively. Thus, a total of 42 PDEA employees coming from the regional office, provincial and city posts, and another 275 respondents representing various sectors of the community such as the youth, professionals, law enforcers, elderly, and business people were considered.

In gathering the needed data, two sets of questionnaires were originally developed by the researcher. Additionally, experts from the academe and the agency were tapped to duly validate the contents of said instruments. To ensure reliability, a try-out was also administered to 50 community members that actually produced a Cronbach alpha of 0.79 suggesting its acceptability.

In particular, the first set was intended for PDEA personnel that basically solicited information on the two essential programs, namely: supply reduction and demand reduction. Respondents have evaluated pertinent indicators of the program utilizing a rating scale as: 5 (Outstanding), 4 (Very Satisfactory), 3 (Satisfactory), 2 (Fair), and 1 (Poor).

On the other hand, the second set was designed for the community members in gathering facts relative to their awareness level. Respondents evaluated each indicator following a rating scale as: 5 (Fully Aware), 4 (Aware), 3 (Moderately Aware), 2 (Unaware), and 1 (Fully Unaware). Documentary analysis was used as well in collecting data on agency accomplishments derived from official records such as number of arrests affected, number of drug law enforcement operations, amount of drugs seized, and the number of cases filed in court.

In data gathering, the researcher merely adopted the herein flow chart as shown (see Figure 2).

In statistical treatments, the researcher made use of both the descriptive and inferential tools. To describe the implementation of the PDEA programs and the level of community awareness, the computation of mean and standard deviation was done. For the agency's common problems and accomplishments such as number of arrests, drug law enforcement operations, amount of seized drugs, and filed cases in court, the frequency count was applied. Finally, the Pearson product-moment correlation was used to determine the direction and degree of relationship of PDEA's programs to community awareness and the agency's accomplishments. All calculations were done using SPSS Version 17 after being encoded in Microsoft Excel worksheets. Appropriate hypothesis testing was performed at the 0.05 level of significance. 


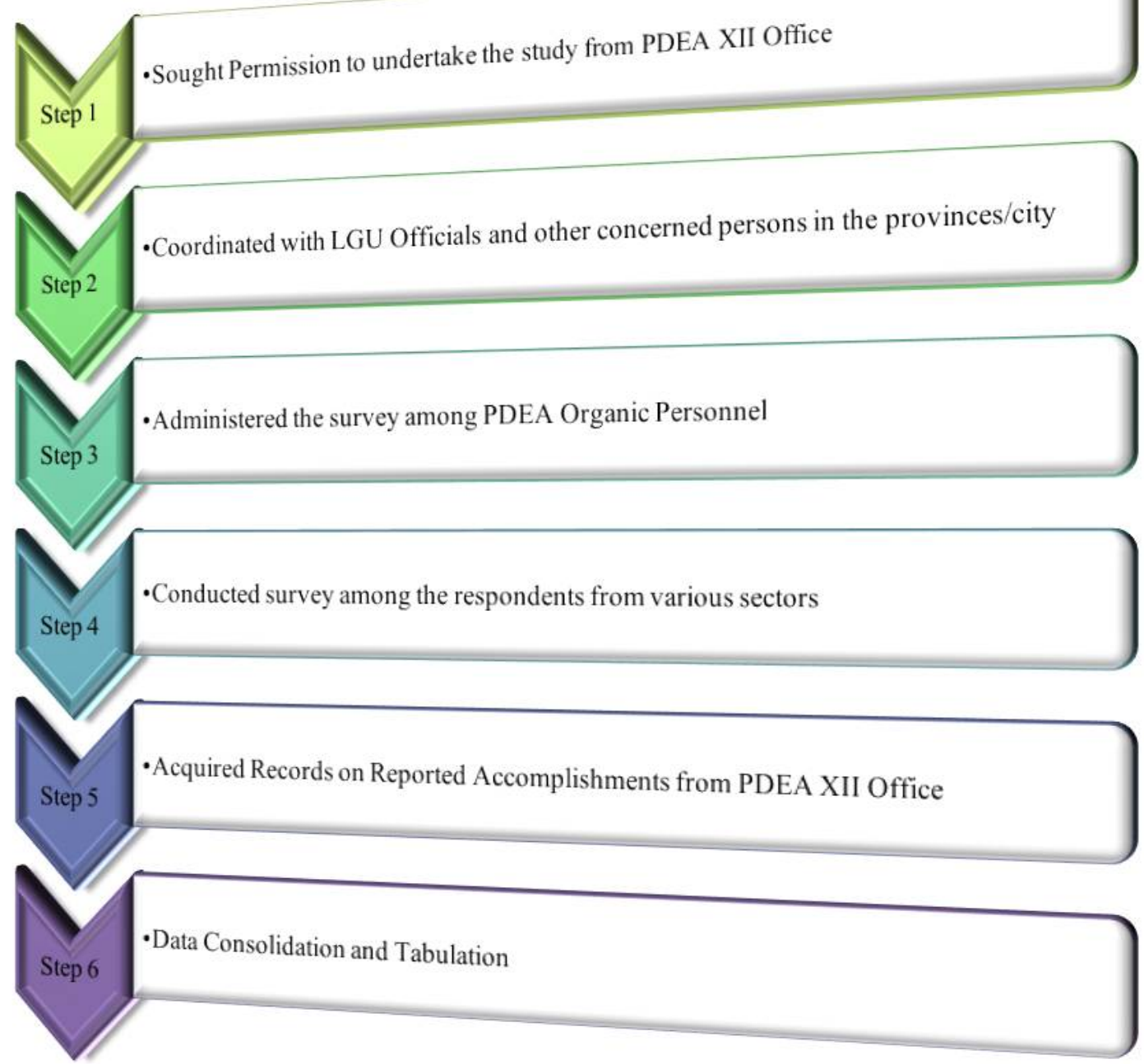

Figure 2. Data gathering flow chart.

\section{Results and Discussions}

With the foregoing methodologies, the study derived these major findings:

\section{PDEA Program Implementation}

(1) On demand reduction program, both information campaigns $(\mathrm{M}=4.17, \mathrm{sd}=0.22)$ and inter-agency collaboration activities $(\mathrm{M}=4.02, \mathrm{sd}=0.08)$ were found to be implemented at "very satisfactory" level;

(2) Likewise, supply reduction program was also implemented consistently at "very satisfactory" level as shown by these means and deviations: intelligence operations $(\mathrm{M}=4.11, \mathrm{sd}=0.08)$, narcotics investigations $(\mathrm{M}=4.23, \mathrm{sd}=0.13)$, and conduct of compliance investigations $(\mathrm{M}=4.00, \mathrm{sd}=0.16)$;

(3) By and large, the PDEA programs on demand and supply reduction were found to be well-implemented.

\section{Community Awareness}

(1) In terms of dangerous drugs and controlled precursors, and essential chemicals, the community members gave a rating of "aware" $(\mathrm{M}=4.01, \mathrm{sd}=0.82)$; 
(2) The community members rated their awareness on the provisions of RA 9165 as "aware" $(\mathrm{M}=3.95$, $\mathrm{sd}=0.35)$;

(3) In terms of common causes of drug use/abuse, they gave the same rating of "aware" $(\mathrm{M}=4.05$, $\mathrm{sd}=0.04)$;

(4) In terms of adverse effects on health of using dangerous drugs, the community members gave a rating of "aware" $(\mathrm{M}=4.03, \mathrm{sd}=0.08)$;

(5) In general, the community was found to have knowledge and understanding of the dangerous drugs and controlled precursors and essential chemicals, provisions of RA 9165, common causes of drug use/abuse, and adverse effects on health of using dangerous drugs $(\mathrm{M}=4.01, \mathrm{sd}=0.37)$.

\section{Agency Accomplishments}

(1) In five local government units in Region XII involved in the study, the PDEA had arrested a total of 102 groups/persons in 2012;

(2) The agency had apprehended the foregoing drug criminals from the 78 buy-bust operations conducted during the year;

(3) From these operations, a total of 23,408 grams of drugs were seized and used as evidences in litigation;

(4) Seized drugs were included in the evidence for the 145 cases filed in court by the agency against drug criminals.

\section{PDEA Programs and Performance}

(1) It was found out that the implementation of PDEA programs and the level of community awareness were significantly related $\left(r_{\text {comp }}=0.95>r_{\operatorname{tab}(0.05)}=0.8114\right)$;

(2) Contrary, the implementation of PDEA programs was not related to the agency performance, such as average number of arrests $\left(r_{\text {comp }}=0.41\right)$, buy-bust operations $\left(r_{\text {comp }}=0.56\right)$, amount of drugs seized $\left(r_{\text {comp }}=\right.$ $0.62)$, and cases filed in court $\left(\mathrm{r}_{\mathrm{comp}}=0.47\right)$.

\section{Major Problems of PDEA}

(1) Vehicles for intelligence and anti-narcotic entrapment operations are the same. This resulted to the drug criminals' familiarity and easy recognition of the same that prompted them to escape and eventually evade arrest during operations;

(2) PDEA agents are less effective due to work burnout. It happened most likely when same agents did tiresome multitasking responsibilities like clerical works, field operations, and appearing in courts during litigation;

(3) Clogging of drug cases in courts leads to slow resolution of crimes. Aside from the many criminal and civil cases being filed in courts every day, the drug cases are added to the bulk causing further congestion of unresolved cases.

\section{Conclusions and Recommendations}

With the foregoing findings, it is concluded that PDEA programs on demand and supply reduction were well-implemented. Apparently, the community members have knowledge and understanding relative to dangerous drugs, controlled precursors and essential chemicals, provisions of RA 9165, common causes of drug use/abuse, and adverse effects on health of using dangerous drugs. Besides, it was ascertained that the agency performed well through the substantial arrests made, amount of drugs seized, buy-bust operations 
conducted, and cases filed in courts. It was also verified that the implementation of PDEA programs was related to the awareness level of the community. Nevertheless, said program implementation was proven not related to agency accomplishments.

Considering the results of the study, it is recommended that relevant and sufficient budget may be appropriated to PDEA by Congress for the purpose of increasing its manpower, procuring the necessary and proper vehicles, conducting more anti-drug campaigns and advocacies, as well as providing professional development opportunities to personnel. It is equally important to consider establishing a special court to exclusively attend to all drug-related cases for a speedy yet judicious resolution of the same. Another study is likewise suggested to perhaps explore the apparent effect of government allocation to drug-related crimes.

\section{References}

ASEAN Economic Community (AEC). (2007). Retrieved from http://www.asean.org

Illegal-drug abuse now an epidemic in the Philippines. (2008). Retrieved from http://www.mabuhayradio.com

KidsHealth Organization. (2010). Know drugs. Retrieved from http://kidshealth.org

National Drug Intelligence Center. (2006). The impact of drugs on society. Retrieved from http://www.justice.gov

PDEA Annual Report. (2010). PDEA Academy, Camp General Castañeda, Cavite, Philippines.

Philippine Drug Enforcement Agency (PDEA). (2009). PDEA Modules. PDEA Academy, Camp General Castañeda, Cavite, Philippines.

Republic Act No. 9165. (2007). Comprehensive Dangerous Drugs Act of 2002. Retrieved from http://en.wikipilipinas.org

Reyes, D. (2008). Prosecution in the Philippines. Retrieved from http://www.article2.org

Rojas, A. (2009). Ideal community. Retrieved from http://www.mightystudents.com

Sanchez, C. A., \& Agpaoa, F. B. (1997). Contemporary social problems and issues (3rd ed.). Manila: National Book Store.

United Nations General Assembly. (1998). Resolution S-20/2 on Political Declaration. UN Headquarters, NY, USA.

United Nations Office on Drugs and Crime (UNODC). (2011). Drug demand reduction. Retrieved from http://www.unodc.org

United Nations Office on Drugs and Crime (UNODC). (2014). World Drug Report 2014. Vienna: United Nations Publication. 